\section{Urban Design as a Catalyst for Advancing Architectural Education}

\author{
Joongsub Kim \\ Lawrence Technological University
}

\begin{abstract}
New approaches to improving architectural education have emerged in recent years, but comprehensive research that investigates the roles that urban design can play in promoting positive changes in architectural education and pedagogy is scarce. Despite urban design's close alliance with architecture, many in the architectural discipline seem to lack a coherent understanding of what urban design can offer to architectural pedagogy. Following an in-depth review of relevant literature, this paper briefly outlines the history, goals, methods, characteristics, and benefits of urban design. This lays the foundation for proposing four approaches to advancing architectural education and pedagogy: facilitating (promoting consensus about design), grounding (promoting logical underpinning, inquiry by design, and evidence-based design), convening (promoting social design), and designing therapeutically (promoting environmental sensibility). Findings and lessons drawn from other fields are also used to support the four approaches. The paper concludes by discussing the implications of its findings and suggesting areas for future research.
\end{abstract}

\section{Introduction}

Urban design principles are used to create the physical environment in which we situate human settlements. It addresses the large-scale organization and design of the city. Principles of design help us arrange buildings and the space between them into a multidimensional expression of human needs and desires. Urban design is a holistic and integrative field whose practitioners must synthesize a wide spectrum of academic and practical disciplines to understand how building design proposals relate to the natural, physical, socio-economic, political, and cultural environments in which they are situated. Thus, urban design draws together place-making, environmental responsibility, social equity, and economic viability into the process of creating satisfying places. In this regard, urban design plays a role in not only establishing the infrastructure and the underpinnings for building design, but also in bridging the gap between architecture and other disciplines that apply principles of urbanism in various ways. Yet although studies have shown that urban design benefits architecture in many ways, it remains a neglected element in architectural education. How can urban design promote positive changes that improve architectural education and pedagogy?
This paper answers that question by exploring the benefits that urban design provide to the art and craft of building design. It considers how urban design can better inform designers about, and help them make use of, the increasingly complex cultural, ecological, and economic contingencies that every building design project faces; it examines the role of urban design in establishing infrastructure and foundations for the changing art of building; it links architecture to urbanism; and in particular it discusses how urban design can help improve architectural education.

Architectural education today does not give students the skills and knowledge they need to address all the factors that must be incorporated into a design project. Including urban design perspectives in architectural curricula could improve architectural education by providing students with a broader set of principles with which to consider site- and areaspecific design features. Urban design is an interdisciplinary profession, integrating urban planning, architecture, landscape architecture, environmental studies, and the social sciences. Urban design schemes reflect the natural, physical, socio-economic, political, and cultural environments of a site. The profession's focus on the public realm forces designers to address large-scale building and spatial issues. To show how increasing the contribution of urban design could improve architectural education, the paper identifies four approaches based on urban design perspectives that should advance architectural pedagogy: facilitating (promoting consensus about design), grounding (promoting logical underpinning, inquiry by design, and evidence-based design), convening (promoting social design), and designing therapeutically (promoting environmental sensibility).

\section{A Brief History of Urban Design in Context}

Urban design is a relatively young profession in comparison with architecture and urban planning. Where urban planning has a focus on organization and use of buildings and land, urban design focuses on design of the spaces between buildings. The term 'urban design' replaced 'civic design' in the late 1960s, reflecting a movement away from a primary design focus on major municipal or civic buildings, such as city halls, libraries, opera houses, and museums (Lang, 1994, p.453; Cullingworth \& Caves, 2003). Many universities offer highly structured, advanced degree curricula in architecture and urban planning; urban design fits in as a specialty within such degree programs or as a piecemeal course offering within the broader curriculum. Elements of urban design have, however; existed since antiquity. Historically, social 
order has been imposed on cities through rationality and geometry (Curl, 2006, p.1; Larice \& Macdonald, 2007). More recently scholars have turned to urban design to address a perceived lack of sound planning and a deterioration of the urban social order.

Cities have suffered from rapid technological advances and the increasing concentration of urban populations. Urban designing has become increasingly complex as the range of human activities grows, communication processes become more diverse, new ways of fitting geometries together are found, and the rate of physical changes accelerates (Lang, 1994, p. 453; Moor \& Rowland, 2006). Following World War II, the United States experienced a boom in suburban development based on detached single-family homes in neighborhoods and the convenience of the automobile. From the urban design perspective, suburban sprawl threatens to destroy the public realm through environmental degradation and over-consumption of resources (Krieger, 2006; Kelbaugh, 2002). Critics of these trends have been pushing the built environment professions to rediscover the classic principles of urbanism: walkable streets, human-scaled buildings, an active public realm, and meaningful and context-relevant civic places (Larice \& Macdonald, 2007, p.1; Krieger, 2006).

Various design paradigms have significantly influenced urban design. Modernism was concerned with inventing the most efficient and hightech design solutions possible. Kelbaugh contends that designers believed that with a sufficiently rational approach such solutions would become self-evident (Kelbaugh, 2002, p. 58). Yet such a 'machine aesthetic' often reduced social interaction in the bargain. Social activism during the 1960s and 1970s led to citizen participation and the consideration of social needs in planning and design. Postmodernism emerged in the 1970s as a rejection of the Modernist machine aesthetic, inviting theoretical influences on design from the fields of linguistics, philosophy and history (Ellin, 1999; Frampton, 2007b; Kelbaugh, 2002, p.66). Postmodernism restored eclecticism, historicism, and pluralism resulting, in the 1980s, in buildings that overflowed with an excess of architectural forms and building materials (Frampton, 2007b; Kelbaugh, 2002, p. 67). The French Postmodernist Henri Lefebvre called for a materialist investigation of urban space (Mehrotra, 2005, p.35). Followers of Lefebvre, such as the "postmodern geographers" David Harvey and Ed Soja, called for "reading the city as if it were a text" to tease out hidden meaning in elements of everyday life (Mehrotra, 2005, p.35). Thus were the 1980s dominated by Postmodernism and Deconstructivism (Larice \& Macdonald, 2007; Mehrotra, 2005, p.35). From the late 1980s through the 1990s, Deconstructivists utilized literary theory and fractal geometry (Frampton, 2007b; Kelbaugh, 2002, p.69), but Deconstructivists tended to express the complex crosscurrents of city life in terms of single buildings rather than the broader urban fabric (Kelbaugh, 2002, p.69). While this theme aimed to reject the technological inspirations of past movements, it failed to address the human scale and tended to fragment the city rather than bringing its elements together.
Since the 1980s, urban designers in the United States have focused primarily on large-scale site planning to create maximum profit for developers (Larice \& Macdonald, 2007, p.462), intensifying suburban sprawl and following social norms that no longer apply (Krieger, 2006; Kelbaugh, 2002, p.49). More recently, however, U.S. urban design has been reshaping itself, forging a kind of comeback by critiquing prior forms of urbanism, fueling a surge in design charettes, competitions, essays, books, articles, and projects that attempt to reform contemporary and Modernist urban paradigms (Kelbaugh, 2002, p.48). Kelbaugh identifies the three most-influential contemporary urbanisms-Everyday Urbanism, Post Urbanism, and New Urbanism-paralleling contemporary architectural philosophies (Kelbaugh, 2002, p.170). Everyday Urbanism, which is informal, conversational, non-utopian, and emphasizes culture more than design as a determinant of human activities (Kelbaugh, 2002, p. 171), seeks the spectacular in everyday experiences, such as people setting up shop in parking lots (Chase et. al., 1999; Mehrotra, 2005, p. 25). In contrast, Post Urbanism, which seeks to inspire awe in sophisticated consumers, is Poststructuralist in ideology and sensational in aesthetic (Larice \& Macdonald, 2007; Kelbaugh, 2002, p.171). Post Urbanism eschews consideration of shared values in such a fragmented culture-its distrust of order is meant to be liberating (Kelbaugh, 2002, p.173). New Urbanism, on the other hand, is utopian or idealistic in that it aspires to reform the social and civic ethic by mixing diverse groups of people and dissimilar land uses (Talen, 2005; Kelbaugh, 2002, p. 170). New Urbanism addresses contemporary social norms by accommodating smaller households, designing more compact developments, reducing dependence on the automobile, and returning to traditional neighborhood design (Dutton, 2000; Kelbaugh, 2002, p. 171; Duany et. al., 2001). Both architects and urban designers contribute to creating the coherent sense of urban place that characterizes New Urbanism.

Throughout its history, urban design has embraced the public realm, the restoration of which has become a priority. The question is: Should architecture not also address the social, cultural, economic, physical, political, and psychological concerns of urban design? How does architecture differ from urban design in this respect? We now address that and other related questions.

\section{The Relationship between Urban Design and Architecture}

Urban design links architecture to the designed built environment and functional urban infrastructure. The current focus on urban design continues the age-old effort to consciously shape and reshape human settlements by establishing design rules (Lang, 1994, p.453). Architects also create rules, inspired by sites, mathematics, movements, patterns, or any number of factors that they impose on the design process.

Although they work within the same realm, architects design buildings while urban designers design the spaces between them. Architects tend to work with individual or corporate clients, with whom they negotiate 
to determine which factors should shape urban buildings. Some collaboration occurs, yet the practitioner is primarily responsible for the design. In building design commissions, clients delegate authority to professionals mainly to benefit from expertise about style, methods, cost, materials, and so on (Zeisel, 2006, p.50). Yet in architectural negotiations on larger-scale projects for corporate clients the user is rarely part of the equation. It is, quite simply, difficult to plan for the needs of user clients, because they are neither well-known nor readily available (Zeisel, 2006, p.50). Zeisel (2006) uses a diagram to illustrate the gap between the client and the user of an architectural design (see a figure entitled "The user needs gap" on p.50 in his book).

Since urban design clients tend to be public bodies such as city agencies or universities, they are more likely than are corporate clients to assist urban designers by providing information about the needs of anticipated user clients. After all, such urban clients typically undertake a project with specific groups of user clients in mind, about whom they may already have pertinent data. Where such data do not exist, they have data-gathering resources at hand and are therefore better able-and, in light of their public responsibility, more willing - to help urban designers investigate the needs of user clients. In this sense, then, principles of urban design may help architects meet the needs of user clients.

Lang's distinction between two basic intellectual processes, namely, divergent thinking and convergent thinking, sheds light on another aspect of the relationship between architecture and urban design: the contrasting modes of thought that characterize the two disciplines (Lang, 1994, p.443). Architects tend to practice convergent thinking while urban designers practice divergent thinking. Convergent thinking is regarded as more creative because it involves identifying and generating patterns that are not only new but also have utility in terms of the problems they address (Lang, 1994, p.443). Divergent thinking generates possible ideas or design patterns in its own right, but it is through convergent thinking that those ideas are synthesized creatively (Lang, 1994, p.443). Methods used by urban designers to encourage divergent thinking frequently include morphological analysis, metaphorical thinking, and brainstorming (Larice \& Macdonald, 2007; Lang, 1994, p.443).

The integrative, multi-disciplinary nature of urban design promotes divergent thinking. Urban design is gradually developing an identity that takes it beyond its traditional role of filling in the intellectual and professional gaps between city planning and architecture. Without abandoning its traditional role, urban design as a discipline is increasingly becoming its own entity (Krieger, 2006; Lang, 1994, p.454).

\section{Comparing the Educational Contexts of Architecture and Urban Design}

Architectural education follows the model of an individual working in a studio setting and periodically presenting plans at a design review.
Meanwhile, urban design often adds a research component to its typically more collaborative studio. Even when architecture and urban design education programs are located within the same college or facility, there is little overlap between the two departments. As figure 1 suggests, the history of education for urban designers, urban planners, and architects mirrors that of their respective practices.

The master-apprentice model began in the late nineteenth century and continues today. Studio pedagogy stems from French traditions associated with the Ecole des Beaux Arts. The American Institute of Architects student task force quotes Fisher (2000) on the subject of William Ware and Richard Morris Hunt, who taught students to respect "the unquestioned authority of the critic, the long hours, the focus on schematic solutions, the rare discussion of users or clients" (AIAS, 2002, p.8). Principles from the German Bauhaus school were imported into American university programs when professors immigrated from Nazi Germany to the U.S. (AIAS, 2002, p.7). Two notable educators came to head American architecture schools: Walter Gropius at Harvard University and Mies van der Rohe at the Illinois Institute of Technology (AIAS, 2002, p.7). Teaching at early Modernist schools such as the Bauhaus made students believe that by looking hard and deep enough inside a problem, the designer could unlock solutions that were rational and inevitable outcomes, uncontaminated by preconception, precedent, or tradition (Kelbaugh, 2002, p.57). The fundamental ideas and ways of thinking embedded within these primary influences have shaped and sustained studio culture (AIAS, 2002, p.8). Urban design did not emerge until social architecture and participatory design came into play in the 1960s. At present, architecture and planning are still the main courses of study for the built environment professions. Developed partly in response to criticism that architectural education neglects the social component, the curriculum followed in urban design education may help architects improve their training.

In 2002 the American Institute of Architecture Students (AIAS) created a report on the current state of architectural education and their hope for future improvements in the academic setting. The problems pointed out by the report could be addressed by increasing the social component in architectural education through increased collaboration with urban design educators. The report also includes a list of myths commonly held by students in architecture schools. These myths may contribute to the tendency for students to feel isolated from other areas of study, including urban design, due to the heavy time commitment and intensity of architecture programs. Such myths, as noted by students in the AIAS task force include the following: "students should not have a life outside of architecture school"; "the creation of architecture should be a solo, artistic struggle"; and "the best ideas come only in the middle of the night" (AIAS, 2002, p.8). In addition to being socially isolated, architecture students also often believe that studio time should take precedence over other academic activity: "design studio courses are more important than other 


\begin{tabular}{|c|c|c|c|c|c|c|c|c|c|}
\hline \multicolumn{10}{|c|}{$\begin{array}{l}\text { A brief history of American architecture and planning education } \\
\text { Sources: Webster (2005) and Kreditor (1990) }\end{array}$} \\
\hline 1850 & 1890 & 1990 & 1940 & 1950 & 1960 & 1970 & 1980 & 1990 & 2000 \\
\hline \multirow{3}{*}{$\begin{array}{l}\text { Enlightenment: } \\
\text { aristocrats learn } \\
\text { 'correct values' } \\
\text { on the 'grand } \\
\text { tour' of ancient } \\
\text { architecture in } \\
\text { Greece and Italy }\end{array}$} & \multirow[t]{2}{*}{$\begin{array}{l}\text { Master- } \\
\text { apprentice model } \\
\text { taught by tutor in } \\
\text { ateliers }\end{array}$} & \multirow[t]{2}{*}{$\begin{array}{l}\text { Instructor } \\
\text { produces and } \\
\text { presents student } \\
\text { work for review } \\
\text { by a panel of } \\
\text { experts }\end{array}$} & \multirow[t]{2}{*}{$\begin{array}{l}\text { Post-war } \\
\text { building boom } \\
\text { creates a } \\
\text { demand for } \\
\text { architects }\end{array}$} & \multirow{2}{*}{$\begin{array}{l}\text { Public schools } \\
\text { establish colleges } \\
\text { of architecture } \\
\text { to produce more } \\
\text { architects } \\
\text { Post-war students } \\
\text { present their own } \\
\text { work for review for } \\
\text { collective dialogue } \\
\text { and objective } \\
\text { assessment }\end{array}$} & \multirow[t]{2}{*}{$\begin{array}{l}\text { Social } \\
\text { architecture, } \\
\text { participatory } \\
\text { design, urban } \\
\text { studios }\end{array}$} & \multirow[t]{2}{*}{$\begin{array}{l}\text { Post-modernism, } \\
\text { international } \\
\text { style, back-to- } \\
\text { basics }\end{array}$} & & & $\begin{array}{l}\text { Design review } \\
\text { as a 'ritual' in } \\
\text { present-day } \\
\text { architecture } \\
\text { schools }\end{array}$ \\
\hline & & & & & & & \multicolumn{3}{|c|}{$\begin{array}{l}\text { Not much interdisciplinary education, prefer faculty of } \\
\text { influential designers rather than researchers }\end{array}$} \\
\hline & & & $\begin{array}{l}\text { Planning as } \\
\text { a specialty } \\
\text { within other } \\
\text { disciplines: } \\
\text { architecture, } \\
\text { engineering, } \\
\text { public } \\
\text { administration }\end{array}$ & $\begin{array}{l}\text { University of } \\
\text { Chicago defined } \\
\text { planning as an } \\
\text { academic field of } \\
\text { study informed by } \\
\text { social sciences, } \\
\text { arts, and } \\
\text { humanities }\end{array}$ & \multicolumn{2}{|c|}{$\begin{array}{l}\text { Balance professional and academic } \\
\text { view of planning, retain social } \\
\text { science influences, locate program in } \\
\text { professional schools }\end{array}$} & \multicolumn{3}{|c|}{$\begin{array}{l}\text { Distance from planning profession, tendency of } \\
\text { positivist/empirical research, collaborate with other } \\
\text { disciplines, yet not with architects }\end{array}$} \\
\hline
\end{tabular}

Figure 1: A brief history of American architecture and planning education

architecture or liberal arts courses" (AIAS, 2002, p.8). Architects could benefit from expanding the architecture curriculum to include broader urban considerations such as context, landscape, history, culture, large regions, and transportation linkages.

One author studied the event of an architecture review in education, where architecture students present their design work to be critiqued by instructors and professionals. It is acknowledged that school cultures tend to lead students to fear the critique, while instructors or tutors see it as a valuable experience in the design process. The author used a qualitative, naturalistic case study approach that targeted the students' views. Data was collected through non-participant observations and interviews with the students under review as well as the professors. Students assumed the working patterns of higher-level students, toiling 10-24 hours a day, as was the expected norm for the days leading up to the review (Webster, 2005, p.270). The experience was accurately characterized as involving "sleepless nights, snack food, coffee and loud music," which led to tired and anxious student behavior at reviews (Webster, 2005, p.270). Reviewers look for a clear narrative constructed by the drawings and the student presentation. Students do not ask questions because of the complex language used by reviewers and also for fear of being humiliated by the response (Webster, 2005, p.270). The author notes that "the unique ability of architects is to create architecture: That is to say, buildings that objectify cultural values and ideas" (Webster, 2005, p.274). Webster observed that the central theme was the critique, assessment, or legitimization of the students' conceptual thinking and its objectification in design as judged against the reviewers' personal constructions, regarded as representatives of the field of architecture (Webster, 2005, p.274). Students could benefit from reviews that critique on the basis of theory as well as practice. Webster reports that it is ironic that students often discover that the architectural values they apply in practice bear little resemblance to those promoted in schools of architecture, especially via studio critiques (Webster, 2005, p.276).

The architectural profession and professional architecture education could benefit from increased demographic and substantive diversity. Researchers investigated three aspects of the studio culture, which they termed the "hidden curriculum": studio pedagogy, social dynamics, and ideals and expectations (Groat \& Ahrentzen, 1996, p.166). The authors contend that "because it often becomes an all-consuming environment, social dynamics are likely to have a substantial impact on students' experience of their educational milieu" (Groat \& Ahrentzen, 1996, p.167). Subsequently they argue that any curriculum or pedagogical format inevitably privileges particular goals and values; it also conveys an impression, however diffuse, of future career roles or paths (Groat \& Ahrentzen, 1996, p.167). Thus a curriculum that promotes more inclusive content and more flexible structure allows students to see multiple points of view and to seek out skills that apply to their intended career paths (Groat \& Ahrentzen, 1996, p.167). Much of this study surveys the apparent disparities between the perceptions of the university experience of women and minorities and those of male and majority students. The 
authors observe, in a section headed "Student Ideals for Architectural Education," that students frequently identified interdisciplinary breadth and the potential for creative expression as among the true pleasures of architectural education (Groat \& Ahrentzen, 1996, p.174). Yet no matter how much students value architecture's interdisciplinary potential, the architecture curriculum too often minimizes it. Many students see isolation from students in other academic disciplines as an unfortunate but inevitable consequence of the enormous time commitment and charette mentality of the studio (Groat \& Ahrentzen, 1996, p.175). The authors argue that many students perceive the subjective and often negatively charged atmosphere of architectural critiques as a major problem (Groat \& Ahrentzen 1996, p.175). They call for re-evaluating current practice in the studio in order to reform the curriculum with faculty and student input.

With a different but parallel focus, Alan Kreditor, the former Dean of the University of Southern California's School of Urban and Regional Planning, weighs in on the place of urban design in the architecture curriculum. Kreditor proposes that urban design has diverged from architecture since architecture began hiring practitioners as educators even as urban design has followed a social scientific track (1990). Although urban design and planning programs are located close to programs in professional architecture, little collaboration occurs between the two fields. Urban design is more likely to be influenced by outside disciplines such as economics, policy science, law, geography, and business than by architecture (Larice \& Macdonald, 2007; Kreditor, 1990, p.159). Some suggest that cities will benefit from architecture that is better informed by the urban context and urban designers trained in social relevance (Moor \& Rowland, 2006; Kreditor, 1990, p.161). In many cases there is a multidisciplinary rather than an interdisciplinary approach to urban design projects. Kreditor seeks to inform urban design education by linking it to architectural education, which should in the bargain produce architects better skilled at solving urban issues and designing buildings for the public realm (1990):

In recent years, planners have become more regulatory and bureaucratic, hoping to coerce the city (or the corporation) into a more economic, social, and ecological form. After several forays into larger social and urban issues, architects have retreated to more traditional roles, claiming the city cannot be more beautiful than its buildings, and then hoping to serve as designers of those buildings (Kreditor, 1990, p. 160).

Academics and professionals alike have lamented this divergence in roles. Techniques employed in the pedagogy of urban design may help to bring the two design fields closer together. Professors at the University of Cincinnati have, for example, written about the theory and application of four ontological constructs of place in terms of a set of visual attributes as well as product, process, and meaning (Arefi \& Triantafillou, 2006, p.75). In their view conventional urban design techniques such as imageability analysis, figure-ground studies, models, and photomontages rarely help capture the holistic nature of place (Arefi \& Triantafillou, 2006, p.76). They identify challenges for planning and urban design education at various levels of application:

At the conceptual level, the problem is how to define place and seek appropriate teaching and learning methods that help achieve a meaningful urban design. At the practical level, the problem is whether studio teaching should continue to emphasize skill building based on the preconceived notions of urban space rather than on the multilayered notion of place (Arefi \& Triantafillou, 2006, p.75).

A useful table below outlines their four constructs and implementation techniques in the academic setting.

An initial framework for the pedagogy of place in planning and urban design.

\begin{tabular}{|c|c|c|c|c|c|}
\hline Ontology & $\begin{array}{c}\text { Related Concept/ } \\
\text { School of Thought/Theory }\end{array}$ & Major Proponents & Learning Stages & Teaching Style & Pedagogy \\
\hline $\begin{array}{l}\text { Place as a set of } \\
\text { visual attributes }\end{array}$ & $\begin{array}{l}\text { Image, townscape, picturesque, } \\
\text { syntax, visual excitement, } \\
\text { contradiction/complexity, icon- } \\
\text { ography, visual layering, chaos }\end{array}$ & $\begin{array}{l}\text { Lynch, Cullen, Jacobs, Issacs, } \\
\text { Nasar, Hillier, Arnheim, Thiis- } \\
\text { Evensen Venturi, Stern, Jerde, } \\
\text { Boyer, Moughtin }\end{array}$ & (Noticing, representation) & (Authority) & Observation \\
\hline Place as product & $\begin{array}{l}\text { Architectural typology and arche- } \\
\text { types, new urbanism, morphology, } \\
\text { experience economy, staged sets, } \\
\text { theme parks }\end{array}$ & $\begin{array}{l}\text { Rossi, Krier, Duany, Plater- } \\
\text { Zyberk, Caniggia, Maffei, } \\
\text { Conzen, Castells, Banerjee/ } \\
\text { Sideris, Jerde, Pine/Gilmore, } \\
\text { Hillier, Boyer, Sorkin }\end{array}$ & $\begin{array}{l}\text { (Reproduction of ideas, ideas } \\
\text { not well-linked) }\end{array}$ & (Learning by doing) & Problem solving \\
\hline Place as process & $\begin{array}{l}\text { "Place still matters," "being and be- } \\
\text { coming," uneven development, } \\
\text { political economy of place, social } \\
\text { and cultural production of place }\end{array}$ & $\begin{array}{l}\text { Dreier et al., Heidegger, Harvey, } \\
\text { Soja, Lefebvre, Mayo, Pred, } \\
\text { Hayden, Zukin, Castells, } \\
\text { Koolhaas }\end{array}$ & $\begin{array}{l}\text { (Well-integrated, ideas linked, } \\
\text { reflective and well- } \\
\text { structured) }\end{array}$ & (Coinvestigator) & Cumulative knowledge \\
\hline Place as meaning & $\begin{array}{l}\text { Sense of place, sacred and the pro- } \\
\text { fane, mythical and real place, } \\
\text { "betweenness of place," phenom- } \\
\text { enology, territoriality, livability }\end{array}$ & $\begin{array}{l}\text { Norberg-Shulz, Appleyard, Tuan, } \\
\text { Relph, Arefi, Entrikin, Cox, } \\
\text { Rapoport, Clay, Jackson, Day, } \\
\text { Brassi, Hayden, Cosgrove, } \\
\text { Whyte }\end{array}$ & $\begin{array}{l}\text { (Reflective, restructured by } \\
\text { learner-idiosyncratic, or } \\
\text { creative) }\end{array}$ & (Mystical-master) & $\begin{array}{l}\text { Values emphasized, phe- } \\
\text { nomenological intu- } \\
\text { ition, transcendental, } \\
\text { mystical, riddle }\end{array}$ \\
\hline
\end{tabular}

Figure 2: Framework for the pedagogy of place in planning and urban design. (Arefi \& Triantafillou, 2006, p.78) 
To view place as a set of visual attributes is to follow a scientific method in applying theory to identify elements of a place. Considering "place as product" involves elements of both architectural education and urban design in hands-on problem-solving. Problem-solving activities that include "learning by doing" bring urban design education closer to architectural education. The ontological constructs in the figure suggest the diversity and richness of urban design techniques designed to address the complex concerns and issues facing people and their environment, while also providing opportunities to complement or enrich architectural education and pedagogy. I apply these ontological constructs of urban design education to the four approaches to advancing architectural pedagogy outlined in the final section of this paper.

Architecture and urban design education also differ significantly in their respective approaches to the promotion or application of diverse social science and multi-disciplinary perspectives. The architectural curriculum has historically eschewed social science ideas and methodologies. Juhasz questions whether architecture and the physical environment affect people's behavior. It is common for professors, critics, and students, at juries and reviews, to avoid discussing the social, psychological, aesthetic, political, or economic effects of their work (Juhasz 1981, p.2). People tend to address only topics about which they are well-informed or on which they have strong opinions. Indeed, the format of an architecture studio encourages the influence of such personal views and preferences.

Trends in the design world reflect designers' views of culture, politics, and current events. Modernism aimed to achieve a functional and aesthetic product. A shift occurred from the rational to the societal, however, as advocacy planning and citizen-participation emerged from the social movements of the 1960s, limiting the professional's previously prominent role in community-wide projects (Cullingworth \& Caves, 2003; Kelbaugh, 2002). In reaction to the widespread social change of the 1960s many architecture schools brought in social scientists to research social phenomena in relation to design work. This raised questions about and provoked a reexamination of the role of the professions and of the basic disciplines to which they are supposed to be related (Kreditor, 1990; Juhasz, 1981, p.6). And yet academics in architecture have traditionally rejected influence by other departments. Juhasz notes that "in engineering faculties they found themselves shunned as not being quantitative and research-oriented, as being concerned with the aesthetics of design, and as not being hard-headed enough" (Juhasz, 1981, p.5). Thus architecture faculty may view attempts to introduce urban design education methods as a threat to their professional identity. Juhasz postulates that professionals may be more effective in the world of applied knowledge not so much in applying expertise from a given field of inquiry as in bringing together the varying and competing skillsets of "experts"-and more importantly, in informing the concerns of those experts with the "ought" (Juhasz, 1981, p.6). Stated informally, the "ought" is how people think things should be in contrast to how they actually are. Collaboration at its best commingles many fields of knowledge and competencies to create better, more beautiful, and more useful buildings.

\section{Comparing Architectural Design Education in the United States and Europe}

Architectural design in the United States currently focuses narrowly on designing buildings and the spaces within them. In comparison, European educators embrace urban design in architectural education, thus including the spaces between buildings in the design process. Arguably, it is common for architects in the United States to disregard context in architectural design, unless there are specific environmental issues to consider. Some European countries acknowledge the urban issues under a broader definition of the role of the architect:

In most European countries the professional title is 'architect and urbanist,' the latter implying anything from planning to urban design. Urban design is an inclusive activity resulting from the collaboration of many different disciplines: The focus is not the buildings as such but the public realm, and the design of larger areas, at a different scale from that at which architects are normally accustomed to working (Leow 2006, p.1)

Considering what some theorists call 'armature' provides yet another perspective on European and American architectural education. In urban design the term 'armature' may be used to describe infrastructure elements such as light rail for public transportation or a structure to accommodate farmers' market stalls. In this sense building the armature of a space is open-ended, since the activity is undefined and open to possibilities. Urban design courses teach students to consider an area as a whole, as "its structure, armature and public realm are designed first and, from these, ideas emerge for individual sites" (Leow, 2006, p.1). Armature involves an organizational framework or structure within which to house the activity of a city. According to Herb Greene, armature is the "public element in a neighborhood or city core to which space-enclosing structures and ornamental surfaces of individual determination can be added or subtracted" (Greene, 1981, p.1). Greene argues that building armature allows people not normally included in the building process to share input on a project (Greene, 1981). According to Leow, Greene, and other scholars, the concept of armature is more likely to be embraced in the architecture curriculum in the European context than in the American context.

\section{Four Approaches to Improving Architectural Pedagogy}

Our review of current educational approaches and professional practice in architecture and urban design, in both the United States and Europe, provides several lessons that can be summarized according to the four themes introduced above-facilitating, grounding, convening, and designing therapeutically. I explore these themes in detail later in the paper; here I briefly note their affinities with urban design. These 
observations reflect the availability of many resources and opportunities for improving architectural education by more effectively informing its practices with key elements of urban design.

Urban design provides better facilitating capabilities than architecture. Creating a desirable place or environment requires a designer to manage a complex process because placemaking is inherently multi-faceted. Urban design is more likely than architecture to offer diverse tools to handle such a process, partly because urban design incorporates more players and interests at various levels in a coordinated manner.

Urban design lends itself better than architecture to the grounding process. Designing also requires a designer to manage and make sense of complex information, and from there to develop a coherent idea that responds effectively to such information. Urban design by nature embraces complex information about wide ranging variables that transcend architecture's single-building focus and is more likely to use diverse strategies, technologies, and methods at various scales or levels.

Urban design can take better advantage of convening than architecture. A desirable place should provide public meaning and positive environmental sociability in order to create a sense of civic place and community in contemporary society. These concerns, as this paper has illustrated, are major priorities in urban design.

Finally, urban design is the more natural discipline within which to design therapeutically. Desirable places today occupy healthy, comfortable, nature-friendly, and sustainable environments that foster the holistic wellbeing of place users. Urban designers consciously reduce environmental stresses to promote human well-being holistically by building on, making the best use of, and improving various opportunities, resources, and assets drawn not just from buildings, but also from their exterior environments, the spaces between buildings, and surrounding regions.

The four themes summarized here lay the groundwork for and serve as a background to the four approaches that this research proposes. These four approaches are designed to advance a particular aspect of architectural pedagogy using urban design-related research studies that look at the educational context of architecture and urban design. It is worth noting that the four approaches are relevant to architectural education, differ from typical architectural education methods, and make it possible to improve architectural pedagogy.

\section{Facilitating}

The goal of facilitating is to promote design consensus. In reference to the ontological constructs of place outlined above, "place as meaning" deals with subjective perceptions of a place as translated from group experiences (Arefi \& Triantafillou, 2006, p.80). According to that construct, designers should be concerned with the livability, spirituality, and territoriality of a place (Arefi \& Triantafillou, 2006, p.78). This type of information is gathered from residents who experience a place on a daily basis. When working in a group to achieve a design objective it is most constructive to evaluate what is there in order to see what is liked and disliked about the existing context. One method of community decision making by consensus design utilizes a non-ideas-based process. Such a process begins by looking communally at the physical description of a place; Day notes that, in practice, "even though we each see different things, we can all agree on [what is there now]" (Day, 2003, p.38). Day argues that working in this way moves a project "where we want to go quicker, more equitably and with richer multi-dimensionality than any idea debating, synthesizing or bargaining" that might occur with other approaches (Day, 2003, p.38). Figure 3 shows how many scattered views may be combined into a more unified, shared vision through consensusbased design.

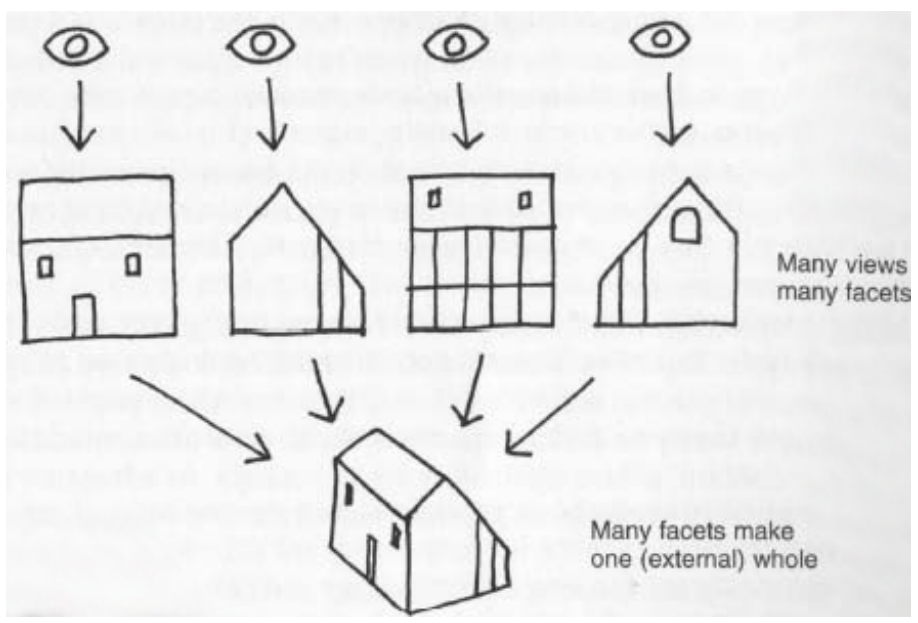

Figure 3: Consensus design (Day, 2003, p.39)

In such a consensus-design process, architects serve as facilitators rather than as architect-directors who impose their design ideologies on everyone else. Promoting diverse views and recognizing the uniqueness of each — even if each view may be limited individually—as well as seeking innovation for synthesizing individual ideas into a shared community value are central to facilitation. The idea of facilitation is also inspired by the works of well-known planning scholars such as Forester (1999) and Faga (2006), who believe that treating diverse views not negatively, as a source of conflicts, but as positive assets saves time and effort for all participants and fosters a constructive design process. Facilitating can also represent an important first step in creating a democratic community vision and building community consensus. 


\section{Grounding}

The goals of grounding are to establish a logical underpinning, undertake inquiry by design, and practice evidence-based design. Grounding may be applied in the academic setting to design disciplines by studying how a place looks, how it functions, its historical influences, and how it makes people feel. Process-based design reads the spirit of a place along with the physical substance before proceeding into designing. Critical Regionalism, for example, stresses the importance of local culture and context. Many other means of studying local context exist. The ontological constructs presented by Arefi and Triantafillou include one means of studying a place according to a set of visual attributes; this follows a scientific method by applying theory to identify elements of a place (Arefi \& Triantafillou, 2006, p.80). Lang suggests a similar approach, advocating contextual studies that focus on identifying existing infrastructure systems (e.g., transportation networks), the characteristics of the built environment that afford a sense of place, and, increasingly, the nature of the biogenic environment (Lang, 1994). These methods illustrate some of the basic techniques of grounding.

Grounding entails carrying out a step-by-step process. Process-based design "must listen to what already is, and grow from it" (Fox, 2000, p.134). This approach to design studies a place objectively on many different levels to read its basic elements such as its physical substance or attributes, but also acknowledges subjective matters such as people's emotional responses to its moods and what the place would say of itself-its essence, genius loci, spirit of place, history of place (Hayden, 1994; Fox 2000, p.134). Process-based designers "allow the buildings themselves to find the forms appropriate to the place and situation by an incarnation process, which mirrors the study process," meaning the designer responds to questions asked in the study (Fox, 2000, p.134). A designer in choosing a material for a building could ask the following questions: "What is its substance? What is its connection to life? Is it pleasant to handle, live alongside? Can it be a contributor to a beautiful place?" (Fox 2000, p.134). Asking questions such as these constitutes a qualitative assessment of a building's elements that complement the necessary technical and quantitative considerations.

Critical Regionalism, for example, grounds its idea on the concept of context, proposing that there is a crisis related to a loss of values in contemporary architecture; according to followers of this school of thought, to resolve this crisis designers must emphasize the revelation of architectural form within a design framework that is sensitive to the local context (Lefaivre, 2003; Fox, 2000, p.176). Kenneth Frampton attributes the loss of social values to the corporate sensibility of Modernism and the disregard of history in Post-Modernism (Frampton, 2007a; Fox, 2000, p.176). Critical Regionalism argues that it is unethical to design in such a way that "neglects the social charge of architecture," and thus "a design aesthetic is ethical if it is context-driven and restores architecture's social focus in a locally sensitive fashion" (Fox, 2000, p.176). Adherents to Critical Regionalism practice ethically by rejecting mass culture while retaining a Modernist commitment to structure that reveals form in the practice of designs that reflect local culture (Lefaivre, 2003; Fox, 2000, p.177). Some have criticized the Critical Regionalist approach to contextual and social design, arguing that, in promoting distinct local culture as a means to rectifying a problematic universal culture, we may be neglecting the issue that those individual cultures are also problematic (Fox, 2000, p.177). One option is to reject mass culture in favor of a single alternative culture that is agreeable to most people yet different enough from the expected, media-driven image of design (Reichert Powell, 2007; Zukin, 1995; Kelbaugh, 2002; Fox, 2000, p.177).

The inclusion of basic ethical guidelines and responsibilities in an architectural curriculum may remedy a situation in which a building rejects its context. It is prudent to ask questions about responsibilities, rights, and utility in architectural practice. Responsibility questions consider the obligations of the architect to other persons, historic preservation, or environmental protection (Fox, 2000, p.177). Ethical questions related to rights ask which parties have rights and how individual parties fall into that hierarchy (Fox, 2000, p.177). Utility regards the usefulness of architectural goods or services according to factors such as social character or the individual preferences of owners, users, or the public (Bunnell, 2002; Fox, 2000, p.178).

As such, grounding is not just about developing a logical argument for one's design but also about searching constantly for a design rationale that promotes social justice, equity, and ethical, democratic, and responsible practices.

\section{Convening}

The goal of convening is to promote social design. The values of social design stem from the advocacy planning and citizen-participation movements of the 1960s in the U.S. Convening pointedly addresses the needs of underrepresented individuals in design. Some applications of convening include service learning and thinking of architecture as public art. Several architecture schools have continuously maintained community design centers and others are reinvesting in various types of community outreach such as design centers, design charettes, and involvement in primary and secondary education (Kelbaugh, 2002, p.59). Service learning has become a popular outlet for urban design and architecture school programs. University architecture and design programs in Michigan utilize community-based outreach studios, such as the "Detroit Studio" at Lawrence Technological University. Arefi and Triantafillou contend that "this approach envisions place as a final 'product' with tangible attributes. By associating these attributes with specific problems, planning services are rendered to underserved communities" (Arefi \& Triantafillou, 2006, p.80). The benefits of this approach include familiarizing students with the complexities of real- 
world planning contexts, helping disadvantaged communities, group learning, and faculty involvement in local redevelopment efforts that would otherwise not be available to those communities (Kelbaugh, 2002; Manning \& Ritzdorf, 1997; Arefi \& Triantafillou, 2006, p.80).

Recent conference proceedings, such as those of the annual conferences of the Association of Collegiate Schools of Architecture (ACSA), include several papers on community-based projects. It is fortunate that a number of schools of architecture across the U.S. have communitybased or community outreach programs. What is unfortunate, however, is that these programs seem to focus mostly on architectural design and design-build projects, neglecting urban scale or urban design projects. As the above review of the current literature in urban design and planning suggests, urban-design-based projects are likely to afford students more diverse and richer opportunities for service learning and social design experiences.

In establishing a basic hermeneutic of architecture it is important to remember what architecture means to people (Lawhon, 2003; Bunnell, 2002; Torsson, 1987, p.11). One approach to social designing is to view architecture as a form of public art, since everyone must experience the built work in some way in their daily lives. Torsson observes that one cannot ignore a work of architecture as she can a painting in a museum or a sculpture in a park (Torsson, 1987, p.13). A designer has the responsibility to the general public to produce architecture with good livability and high aesthetic value, and this cannot be accomplished "without knowledge and understanding concerning those dimensions that lie beyond the most elementary utility of the built environment" (Torsson, 1987, p.13). A practitioner may translate this view of architecture as art into thinking about broader public issues during the design phase, including how their work impacts the general public as well as the environment and the larger regions.

\section{Designing Therapeutically}

The goal of therapeutic designing is to promote a holistic environmental sensibility. Such design is therapeutic insofar as environmentally sensitive design, as suggested by many environmental psychologists (e.g., Gifford, 2002; Preiser et. al., 1991; Kopec, 2006; Cohen et. al., 1986; Malnar \& Vodvarka, 2004), should foster a healthy environment, a sense of comfort, and positive emotional and psychological well-being.

It should be noted as well that architects have an ethical responsibility for environmental stewardship to preserve the environment or at least do the least amount of harm. In many cases, construction is concerned with the appropriation of the environment; natural matter or its attributes are transformed by technical and cultural means in order to satisfy human needs and demands (Cumberlidge \& Musgrave, 2007; Barton, 2005; Torsson, 1987, p.14). It is important that students learn how to balance the need to build and the need to inhabit (Torsson, 1987, p.14; see Figure

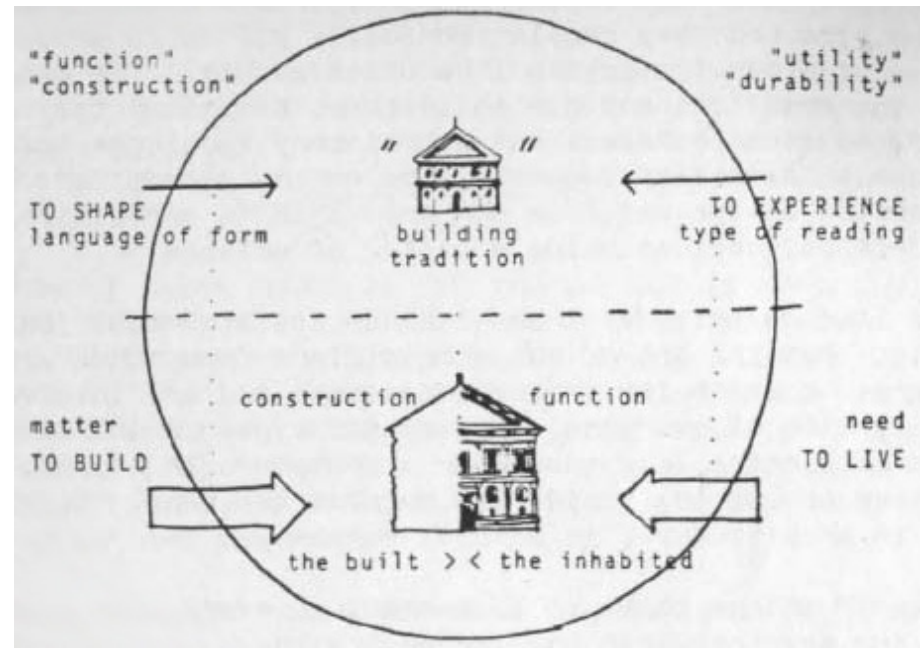

Figure 4: To build and to inhabit (Torsson, 1987, p.14)

4). The built environment is often seen as existing in conflict with nature, but it is possible to find examples where buildings work with nature to achieve desired outcomes. Environmental sensibility does not focus solely on promoting an energy-efficiency, for example, but also seeks holistic benefits within natural and built environments.

Many current movements in design fields, including New Urbanism and Green Building, share an interest in preserving environmental features and addressing them in design. Some key features of sustainable urban design include socially mixed and inclusive communities, the provision of public transportation services, public services that meet a range of needs, and community involvement in decision making about design (Thomas, 2003; Grant, 2003; Farr, 2008). In this context, a desirable sustainable design or sustainable urbanism goes beyond dealing with physical and environmental considerations, rating systems, and energy concerns to address social and psychological concerns.

As such, environmental sensibility deals with the social, psychological, emotional, and physical well-being of all community members and users in a well-balanced and holistic manner in the production of the built environment. Inspired by achievements in environmental psychology, therapeutic designing can bring new insights into, add useful dimensions to, or play a positive role in sustainable design that, arguably, is often narrowly focused even as it sweeps the country and the world.

\section{Conclusion and Areas of Future Research}

This paper has examined the context of education, pedagogy, and practice in architecture and urban design, comparing the American and European approaches while reviewing the relevant literature in architecture, urban design, and planning. 
Although urban design exhibits some limitations, it is well-established as a strong field in its own right with valuable lessons to offer architectural education. While this paper does not argue that architecture is devoid of some positive values that it shares with urban design, urban design offers several unique and valuable assets. For example, while the process-based approach does exist in both architecture and urban design, urban design is, arguably, more process-oriented, as illustrated in the paper. The four pedagogical approaches recommended herefacilitating, grounding, convening, and designing therapeutically—reflect this process-oriented perspective.

Building on various fields such as environmental psychology, sociology, and planning, I suggest these approaches to provide alternative avenues for effecting concrete change in architectural education and pedagogy. I would argue that all four approaches are needed to promote effective change, even though they overlap to some extent. These approaches can be applicable to both building design and the design of cities partly because they are grounded in lessons from social science disciplines that address the impact of various environments on people, while helping to link architecture and urban design. This study is conceptual and explorative in nature and therefore does not address specific practical applications of the four approaches. To do so would require the operationalization of these approaches to make them applicable, measurable, and assessable. That is a task for future studies.

Nevertheless, I argue that each of these approaches provides educators with opportunities to experiment with possible changes in their teaching practices. For example, including urban design in the architecture curriculum could introduce diverse or creative shifts in design method, scale, and focus. Facilitating can teach architectural students how to act as consensus builders in the design process, which would represent a sea-change from the 'archi-director' model that the current education system tends, willingly or unwillingly, to emulate or advocate in many architecture schools. The design process in real-life practice tends to be messy and fraught with many conflicts. Facilitating can help students learn how to turn conflicts into positive energy to build a constructive design process and community vision. Grounding can teach students about developing a rationale for design that is not only beautiful but also ethical, responsible, just, and useful, challenging students to redefine good or successful design and to recognize how current definitions of good design are limited. Convening, on the other hand, teaches students how to provide opportunities for positive social encounters in the production of the built environment and challenges students to redefine and expand the role, meaning, and power of design, especially in the context of helping disadvantaged communities through service learning. Designing therapeutically teaches students about sustainability informed by a holistic environmental sensibility that promotes the well-being of the entire community including its buildings, the natural environment, other built environments, and their users. A therapeutic design perspective can reinforce and even expand the somewhat narrowly defined value of sustainable practice that currently dominates the entire world.

It is possible that some or all of these four approaches may have already been implemented at some schools. If that is true, it may be useful in the future to survey cases where these approaches have been in use and to draw some lessons from them. Perhaps not all of the four approaches are equally suited to certain types of projects. Thus future studies could determine systematically which approaches benefit which types of projects.

Even if educational programs that address the overlaps between architecture and urban design in a multidisciplinary manner are plentiful--and we encounter them when we attend major conferences in architecture (e.g., ACSA Conferences)-we lack scientific evidence that supports their positive impact on students. For example, among recently emerging urban paradigms, landscape urbanism has received much attention (see Waldheim, 2006). Landscape urbanism is a fairly new trend and there has been little empirical research on its effectiveness. It would be useful to survey such programs and new paradigms to see whether they have actually yielded valuable outcomes, whether they have had any positive impact on students, or whether they have allowed students to successfully engage in facilitating, grounding, convening and designing therapeutically during the design process. This would require empirically-based research.

Without denying there may be drawbacks to the recommended approaches, this study takes an important step in a fruitful direction by addressing several ways in which architectural education and pedagogy can be improved according to lessons drawn from urban design education and practice.

Note:

It is acknowledged that Ann-Germaine Kreger, a student assistant at our college, helped the author with the initial draft of this manuscript and with initial data collection.

\section{References}

AIAS. (2002). The Redesign of Studio Culture: A Report of the AIAS Studio Culture Task Force. Washington, DC: American Institute of Architecture Students.

Anthony, K. H. (1991). Design Juries on Trial: The Renaissance of the Design Studio. New York: Van Nostrand Reinhold.

Arefi, M. \& Triantafillou, M. (2005). Reflections on the Pedagogy of Place in Planning and Urban Design. Journal of Planning Education and Research, 25(1), 75-88.

Barton, H. (2005, Winter). A Health Map for Urban Planners: Towards a Conceptual Model for Healthy, Sustainable Settlements. Built Environment, 31(4), 339-355. 
Bunnell, G. (2002). Making Places Special: Stories of Real Places Made Better by Planning. Chicago: Planners Press, American Planning Association.

Chase, J., Crawford, M., and Kaliski, J. (1999). Everyday Urbanism. New York: Monacelli Press.

Cohen, S., Evans, G.W., Stokols, D., \& Krantz, D.S. (1986). Behavior, Health, and Environmental Stress. New York: Plenum.

Cullingworth, B. and Caves, R. (2003). Planning in the USA, 2nd ed. New York: Routledge.

Curl, J. S. (2006) Urban Design: A Dictionary of Architecture and Landscape Architecture. Oxford Reference Online. Oxford University Press. Lawrence Technological University.

Retrieved March 10, 2009 from: <http://www.oxfordreference.com/views/ENTRY. html?subview=Main\&entry=t1.e6127>

Day, C. (2003). Consensus Design: Socially Inclusive Process. Oxford, Great Britain: Architectural Press.

Duany, A. et. al. (2001). Suburban Nation: The Rise of Sprawl and the Decline of the American Dream. New York: North Point Press.

Dutton, J. A. (2000). New American Urbanism: Re-forming the Suburban Metropolis. New York: Abbeville Publication Group.

Ellin, N. (1999). Postmodern Urbanism. New York: Princeton Architectural Press.

Faga, B. (2006). Designing Public Consensus. Hoboken, New Jersey: John Wiley \& Sons.

Farr, D. (2008). Sustainable Urbanism: Urban Design with Nature. Hoboken, N.J.: J. Wiley \& Sons.

Forester, J. (1999). The Deliberative Practitioner: Encouraging Participatory Planning Processes. Cambridge, MA: MIT Press.

Fox, W. (2000). Ethics and the Built Environment. New York: Routledge.

Frampton, K. (2007a). Modern Architecture: A Critical History. London \& New York: Thames \& Hudson,

Frampton, K. (2007b). The Evolution of 20th century Architecture: A Synoptic Account. Wien, London : Springer.

Gifford, R. (2002). Environmental Psychology: Principles and Practice. Colville, WA: Optimal Books.

Grant, J. (Aut 2003). Exploring the Influence of New Urbanism in Community Planning Practice. Journal of Architectural and Planning Research. 20(3), 23453.

Green, H. (1981). Building to Last: Architecture as Ongoing Art. New York: Architecture Book Publishing Co.

Groat, L. N., \& Ahrentzen, S. (1996). Reconceptualizing Architectural Education for a More Diverse Future: Perceptions and Visions of Architectural Students. Journal of Architectural Education, 49(3), 166-183.

Hayden, D. (1994). The Power of Place: Claiming Urban Landscapes as People's History. Journal of Urban History, 20(4), 466 - 485.

Juhasz, J. (1981). The Place of the Social Sciences in Architectural Education. Journal of Architectural Education, 34(3), 2-7.

Kelbaugh, D. (2002). Repairing the American Metropolis. Seattle: University of Washington Press.
Kopec, D. (2006). Environmental Psychology for Design. New York: Fairchild Publications, Inc.

Kreditor, A. (1990). The Neglect of Urban Design in the American Academic Succession. Journal of Planning Education and Research, 9(3), 155-163.

Krieger, A. (2006). Territories of Urban Design. In Moor, M. and Rowland, J. (Eds.), Urban Design Futures. (pp. 18-28). London and New York: Routledge.

Lang, J. (1994). Urban Design: the American Experience. New York: Van Nostrand Reinhold.

Larice, M. and Macdonald, E. (2007). The Urban Design Reader. London; New York: Routledge.

Lawhon, L. L. (2003, Summer). Planners' Perceptions of their Role in Socially Responsive Neighborhood Design. Journal of Architectural and Planning Research, 20(2), 153-63.

Lefaivre, L. (2003). Critical Regionalism: Architecture and Identity in a Globalised World. Munich; New York: Prestel.

Loew, S. (2006). The Perfect Architect is Probably a Good Urban Designer. The Architects' Journal, 224(7), 47.

Malnar, J. and Vodvarka, F. (2004). Sensory Design. Minneapolis: University of Minnesota Press.

Manning, T. and Ritzdorf, M. (1997). Urban Planning and the African American Community: in the Shadows. Thousand Oaks, CA: Sage Publication.

Mehrotra, R. (2005). Everyday Urbanism: Margaret Crawford vs. Michael Speaks. Ann Arbor, Ml: University of Michigan, Alfred Taubman College of Architecture; New York: Distributed Arts Press.

Moor, M. and Rowland, J. (2006). Urban Design Futures. London and New York: Routledge.

Preiser, W., Vischer, J., \& White, E. (Eds.). (1991). Design Intervention. New York: Van Nostrand Reinhold.

Reichert Powell, D. (2007). Critical Regionalism: Connecting Politics and Culture in the American Landscape. Chapel Hill: University of North Carolina Press.

Talen, E. (2005). New Urbanism \& American Planning: The Conflict of Cultures. New York: Routledge.

Thomas, R. (2003). Sustainable Urban Design: An Environmental Approach. New York: Taylor \& Francis.

Torsson, B. (1987). The psychology of architecture as a cultural phenomenon: an architect's perspective. In

Ulrich, R. \& Hygge, S. (Eds.), Research on Environments and People: Methods, Quality Assessment, New Directions: Proceedings of a Multidisciplinary Conference, Gavle, Sweden, June 6-7, 1985. (pp. 10-11). Stockholm: Swedish Council for Building Research.

Waldheim, C. (2006). The Landscape Urbanism Reader. New York: Princeton Architectural Press.

Webster, H. (2005) A Study of Ritual, Acculturation and Reproduction In Architectural Education. Arts and Humanities in Higher Education, 4(3), 265-282.

Zeisel, J. (2006). Inquiry by Design: Environment/Behavior/Neuroscience in Architecture, Interior, Landscape, and Planning. New York: W. W. Norton \& Company.

Zukin, S. (1995). The Cultures of Cities. Cambridge, MA: Blackwell. 